
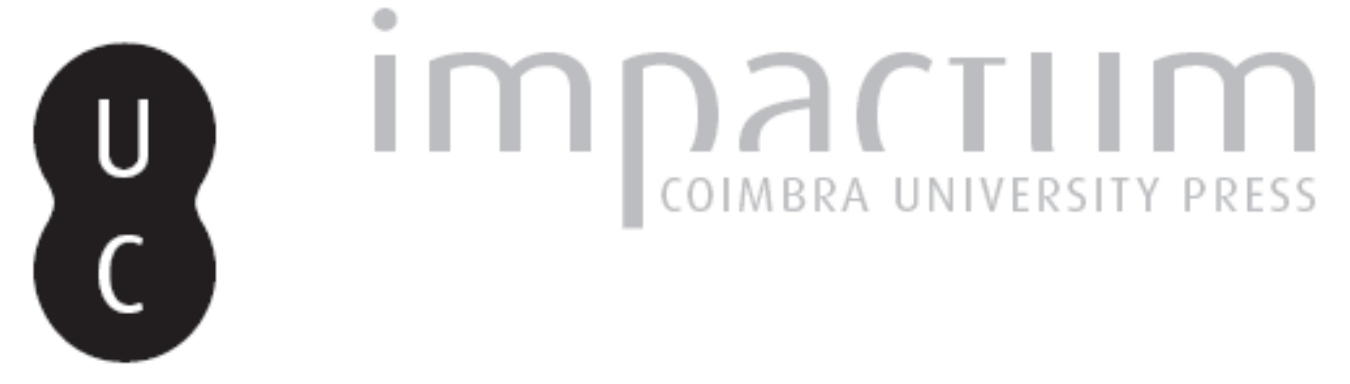

\title{
Terceira edição de um clássico sobre riscos
}

Autor(es): $\quad$ Rebelo, Fernando

Publicado por: Associação Portuguesa de Riscos, Prevenção e Segurança

URL persistente:

URI:http://hdl.handle.net/10316.2/40104

DOI:

DOl:https://doi.org/10.14195/1647-7723_8_9

Accessed : $\quad$ 26-Apr-2023 14:02:25

A navegação consulta e descarregamento dos títulos inseridos nas Bibliotecas Digitais UC Digitalis, UC Pombalina e UC Impactum, pressupõem a aceitação plena e sem reservas dos Termos e Condições de Uso destas Bibliotecas Digitais, disponíveis em https://digitalis.uc.pt/pt-pt/termos.

Conforme exposto nos referidos Termos e Condições de Uso, o descarregamento de títulos de acesso restrito requer uma licença válida de autorização devendo o utilizador aceder ao(s) documento(s) a partir de um endereço de IP da instituição detentora da supramencionada licença.

Ao utilizador é apenas permitido o descarregamento para uso pessoal, pelo que o emprego do(s) título(s) descarregado(s) para outro fim, designadamente comercial, carece de autorização do respetivo autor ou editor da obra.

Na medida em que todas as obras da UC Digitalis se encontram protegidas pelo Código do Direito de Autor e Direitos Conexos e demais legislação aplicável, toda a cópia, parcial ou total, deste documento, nos casos em que é legalmente admitida, deverá conter ou fazer-se acompanhar por este aviso.

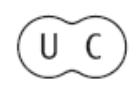




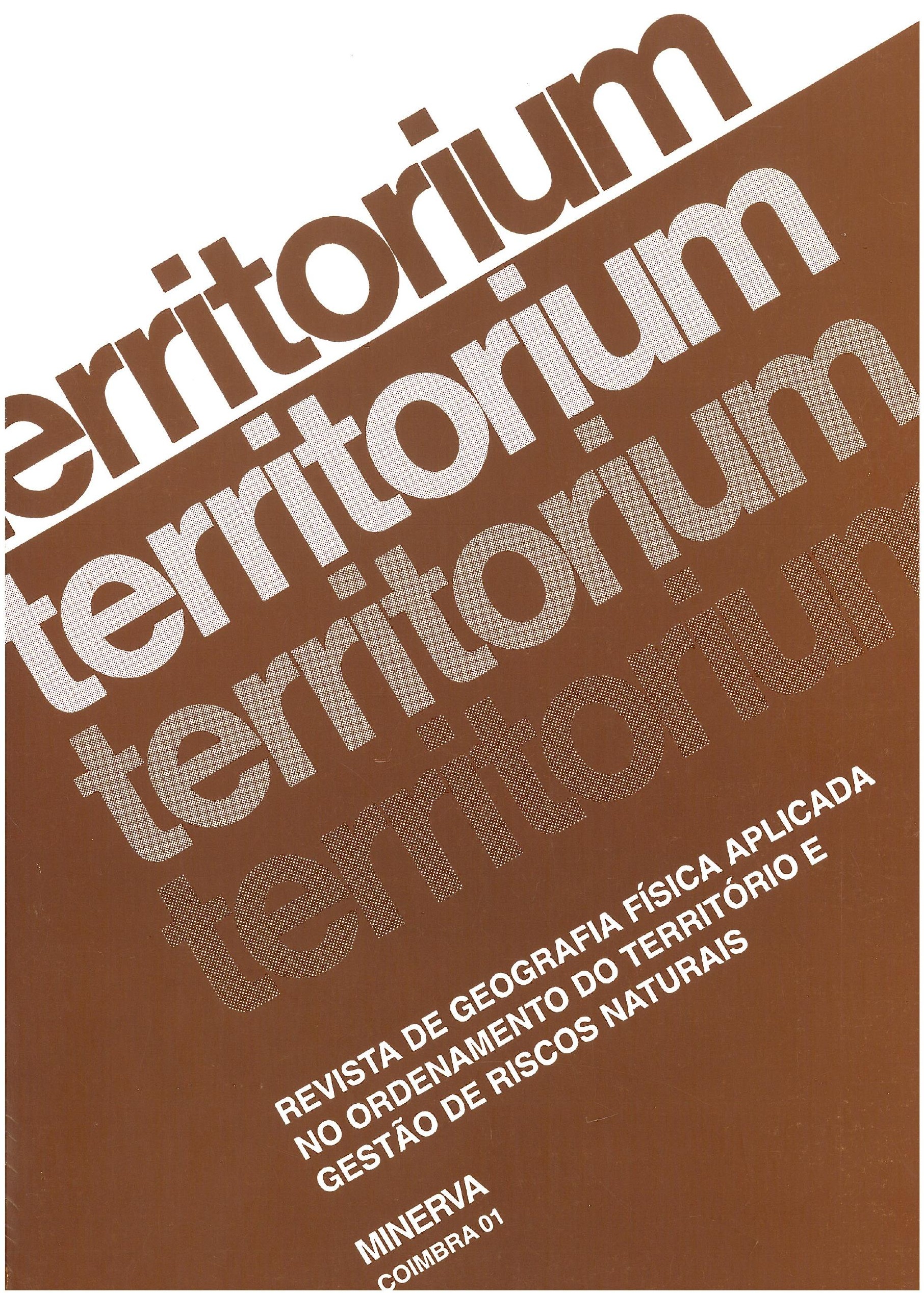




\section{NOTAS, NOTÍCIAS E RECENSÕES}

\section{Terceira edição de um clássico sobre riscos}

\section{Fernando Rebelo}

Da autoria de Keith Smith, Professor Emérito da Universidade de Stirling (Reino Unido), o livro Environmental Hazards. Assessoring Risk and Reducing Disaster veio a lume pela primeira vez em 1991, teve uma segunda edição em 1996 e acaba de ser editado pela terceira vez (London and New York, Routledge, 2001, 392 p.).

Começava já a ser tempo de nos debruçarmos sobre este clássico, pelo que não podíamos deixar passar esta oportunidade para o apresentarmos aos leitores que ainda o não conhecem.

Antes de mais, falemos do título. Sabe-se que o Autor distingue hazard de risk, embora reconheça que alguns cientistas, todavia, não fazem essa distinção - "risk é por vezes tomado como sinónimo de hazard" (p.6). Efectivamente, em bom português, por exemplo, não há lugar para distinção entre essas duas noções; hazard tem sido traduzido por perigosidade, o que não se nos afigura correcto (F. REBELO, $1999 \mathrm{e}$ 2001), até pensando na própria definição de K. SMITH - "processo ou acontecimento ocorrendo naturalmente ou induzido pelo homem com potencial de criar perdas, isto é, uma fonte geral de futuro perigo". Perigosidade é uma qualidade (a qualidade de ser perigoso), nãoé um processo, nem um acontecimento. Outra hipótese de tradução será casualidade, mas trata-se também de uma qualidade (a qualidade de ser casual); no português corrente, todavia, casualidade significa muitas vezes acontecimento ocasional há, por isso, engenheiros que utilizam a palavra casualidade como tradução para hazard. No entanto, se o próprio K. SMITH diz que o hazard tem o "potencial de criar perdas" porque não o havemos de traduzir por risco, atendendo a que nãoé fácil encontrar uma outra palavra?

Dir-se-á que o hazard é anterior à consideração da vulnerabilidade, mas se virmos bem, ao pensar-se em perdas já temos o homem presente, directa ou indirectamente.

Toda esta problemática se relaciona com o título do livro, que, em português, poderia perfeitamente ser "Riscos Ambientais", até porque a alternativa, "Perigosidades ambientais" ou, um pouco melhor, "Casualidades Ambientais" não soaria bem aos nossos ouvidos e, de certo modo, até agrediria a nossa inteligência.

Torna-se, porém, necessário analizar o conteúdo do livro para ver se a dimensão dada ao título com a palavra ambiental corresponde à realidade. É claro que se pretende ir além dos riscos (ditos) naturais, pois se reserva um capítulo aos riscos tecnológicos: como a noção de ambiente é muito complexa, integrando o solo, o ar e a água, como já há trinta anos ensinava P. GEORGE (1971), os riscos tecnológicos são fundamentais no contexto ambiental. Deste modo, K. SMITH está correcto. Não estará correcto quem utilize a mesma expressão ("riscos ambientais") para se referir apenas a riscos naturais ou a uma só categoria destes, como são os riscos geomorfológicos.

K. SMITH dividiu o seu livro em duas partes - "a natureza do hazard" e a "experiência e redução do hazard". Na primeira parte, os capítulos são cinco "hazard no ambiente", "dimensões do desastre", "assessoria do risk e gestão do desastre", "ajustamento ao hazard: aceitando e compartilhando a perda" e "ajustamento ao hazard: reduzindo a perda". É uma sequência de capítulos por vezes um tanto filosóficos, sempre teóricos, embora com alguns quadros e algumas fotografias chamando a atenção para a crua realidade das conisequências das crises.

A segunda parte é fundamentalmente prática, com muitos exemplos, bem ilustrados, sem, todavia deixar de aprofundar algumas explicações teóricas necessárias para a compreensão de mecanismos tanto no respeitante à geodinâmica interna como à geodinâmica externa. Aí estão os terramotos, os vulcões, os movimentos em massa, as grandes tempestades, os hazards biofísicos (onde inclui os incêndios florestais), as inundações, as secas e os hazards tecnológicos.

As conclusões vêm depois e, curiosamente, é no seu contexto que fala em mudanças ambientais e na subida do nível do mar, tal como fala em novos hazards ena necessidade de uma cultura de prevenção.

Environmental hazards. Assessing Risk and Reducing Disaster é um clássico da literatura de riscos em língua inglesa, ao mesmo tempo que se tem de considerar indubitavelmente um grande livro, com muita informação e bem estruturado.

\section{Referências bibliográtícas}

GEORGE, Pierre (1971) - L'emironnement. Paris, P.U.F., Coll. "Que sais-je?", nº 1450, 128 p.

REBELO, Fernando (1999) - "A teoria do risco analisada sob uma perspectiva geogrática". Cademos de Geografia, 18, p. 3-13.

REBELO, Fernando (2001) - Riscos Naturais e Acção Antrópica. Coimbra, Imprensa da Universidade, $274 \mathrm{p}$. 